\title{
An Idiopathic Giant Right Atrium Aneurysm in Old Asymptomatic Patient
}

\author{
Abdallah Almaghraby ${ }^{1}$, Mahmoud Abdelnabi², Yehia Saleh ${ }^{1,3}$ \\ 'Department of Cardiology, Faculty of Medicine, University of Alexandria, '2Department of Clinical and Experimental Internal Medicine, Cardiology and Angiology Unit, \\ Medical Research Institute, University of Alexandria, Alexandria, Egypt, ${ }^{3}$ Department of Internal Medicine, Michigan State University, East Lansing, Michigan, USA \\ ORCID: \\ Abdallah Almaghraby: https://orcid.org/0000-0001-6541-0850 \\ Mahmoud Abdelnabi: https://orcid.org/0000-0003-1211-1982 \\ Yehia Saleh: https://orcid.org/ 0000-0003-3873-5582
}

\section{Abstract}

Giant right atrial aneurysm is an extremely rare cardiac anomaly that can be seen anytime in human life from childhood to elderly. Many cases have no symptoms, others may develop arrhythmias such as atrial fibrillation (AF), and sometimes, thrombi may develop inside the right atrium with risk of pulmonary embolism as well as paradoxical embolism through a patent foramen ovale. This condition can be caused due to cor pulmonale, right ventricular disease, and tricuspid valve diseases, and in extremely rare cases, if all these causes are excluded, it is considered idiopathic. We report a very rare case of an asymptomatic 62-year-old male with a previous history of chronic AF who was incidentally diagnosed with a giant right atrial aneurysm in a preoperative transthoracic echocardiography. He was asymptomatic and he was managed conservatively based on his request.

Keywords: Arrhythmias, atrial fibrillation, giant right atrial aneurysm, thromboembolic events, transthoracic echocardiography

\section{INTRODUCTION}

Giant right atrial aneurysm is an extremely rare cardiac congenital anomaly that can present anytime during fetal life till old age. Most of the cases are asymptomatic, but some present with atrial arrhythmias or thromboembolic complications. ${ }^{[1]}$ Most of the cases are usually diagnosed accidentally through chest X-ray and confirmed by transthoracic echocardiography (TTE) and cardiac magnetic resonance (CMR) if needed. ${ }^{[1]}$

\section{Case Report}

A 62-year-old-male patient was referred for a preoperative TTE before a cataract surgery. He had a previous medical history of hypertension and chronic atrial fibrillation (AF) for which he was treated with digoxin and warfarin and he was totally asymptomatic. On clinical examination, he had bilateral congested pulsating neck veins and pansystolic murmur over the left lower end of the

Submission: 19-04-2019 Revision: 12-06-2019 Accepted: 29-06-2019

Published Online: 13-02-2020

\begin{tabular}{|l|l|}
\hline \multicolumn{3}{|c|}{ Access this article online } \\
\hline Quick Response Code: & Website: \\
& \\
&
\end{tabular}

sternum. TTE [Figures 1-7] revealed an accidentally discovered giant right atrial aneurysm that measures $160 \mathrm{~mm} \times 140 \mathrm{~mm}$ in its dimensions with an estimated volume of $1450 \mathrm{ml}$, and the giant right atrium was compressing the left atrium, the left ventricle, and the right pulmonary artery. The left ventricular systolic function was normal, the tricuspid valve (TV) was normal in morphology with mild tricuspid regurgitation, and the pulmonary valve and the pulmonary artery were also normal in structure and dimensions. Further, multislice computed tomography confirmed the diagnosis. As the patient was asymptomatic, he refused further workup. Hence, the decision was to continue rate control of the $\mathrm{AF}$ and proper anticoagulation.

Address for correspondence: Dr. Mahmoud Abdelnabi, Department of Clinical and Experimental Internal Medicine, Cardiology and Angiology Unit, Medical Research Institute, University of Alexandria, 165 El-Horeya Rd, Al Ibrahimeyah Qebli Wa Al Hadrah Bahri, Qesm Bab Sharqi, Alexandria, Egypt. E-mail: mahmoud.hassan.abdelnabi@outlook.com

This is an open access journal, and articles are distributed under the terms of the Creative Commons Attribution-NonCommercial-ShareAlike 4.0 License, which allows others to remix, tweak, and build upon the work non-commercially, as long as appropriate credit is given and the new creations are licensed under the identical terms.

For reprints contact: reprints@medknow.com

How to cite this article: Almaghraby A, Abdelnabi M, Saleh Y. An idiopathic giant right atrium aneurysm in old asymptomatic patient. Int $\mathrm{J}$ Cardiovasc Acad 2020;6:29-31. 


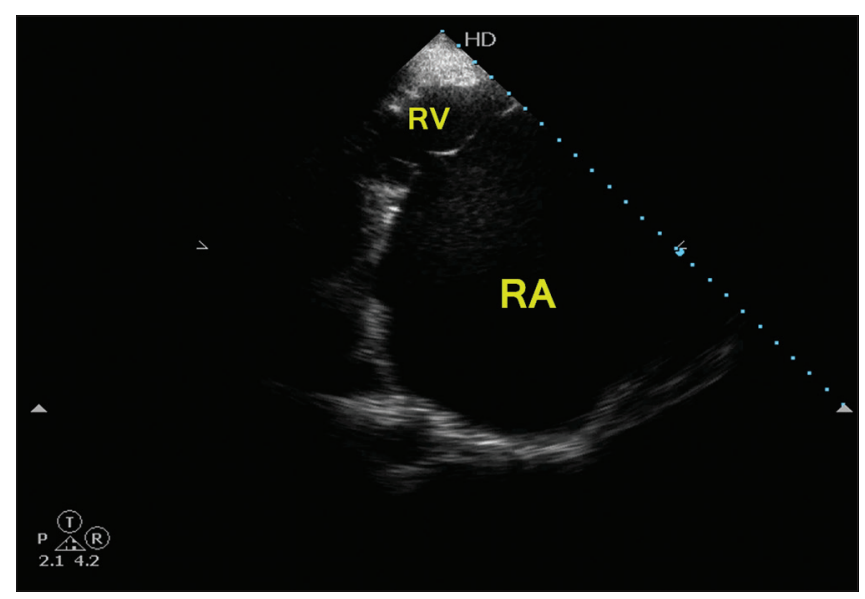

Figure 1: Two-dimensional transthoracic echocardiography right ventricular inflow view showing huge right atrial aneurysm

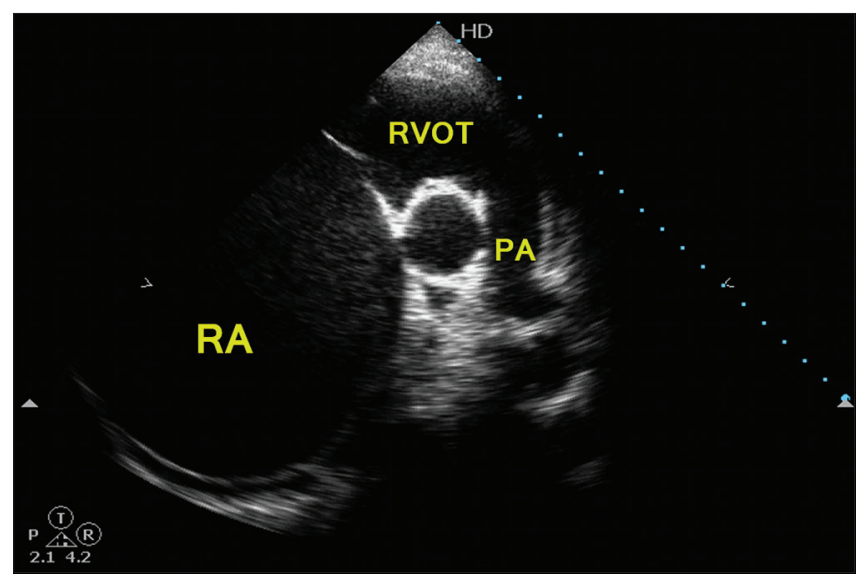

Figure 3: Transthoracic echocardiography at the level of great vessels



Figure 5: Transthoracic echocardiography subcostal view showing dilated inferior vena cava (IVC)

\section{Discussion}

Giant right atrial aneurysm is an extremely rare cardiac condition of unknown origin with controversial etiology either congenital or acquired. ${ }^{[2]}$ Some prefer to consider it idiopathic

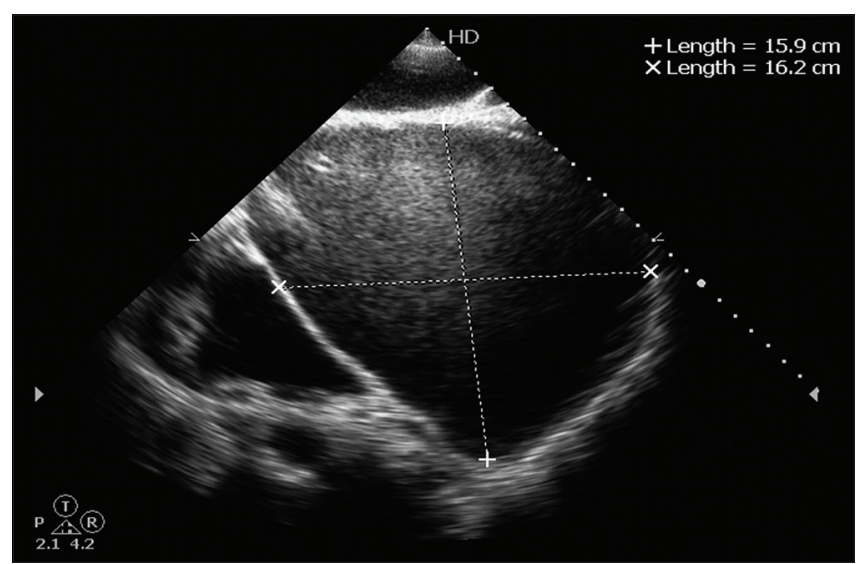

Figure 2: Transthoracic echocardiography showing huge right atrial aneurysm measuring $16 \mathrm{~cm} \times 16.2 \mathrm{~cm}$

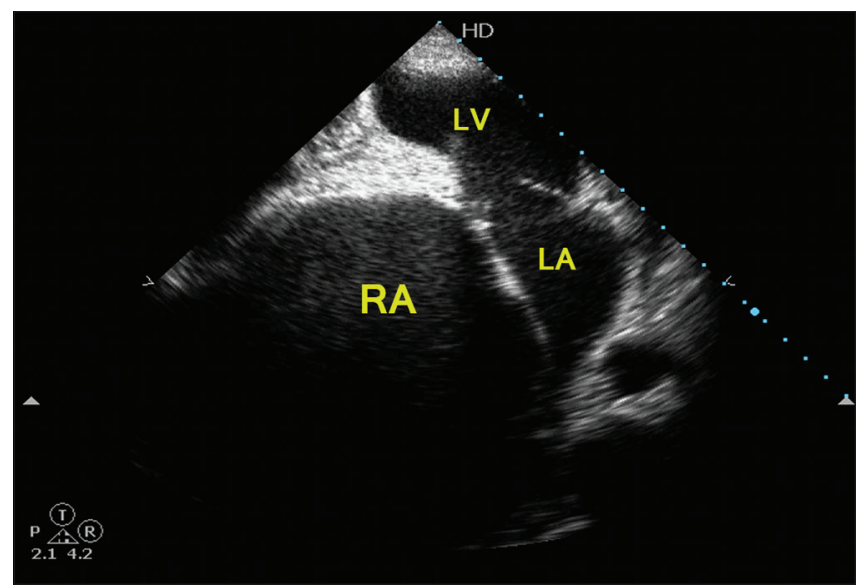

Figure 4: Transthoracic echocardiography apical four-chamber view showing huge right atrial aneurysm

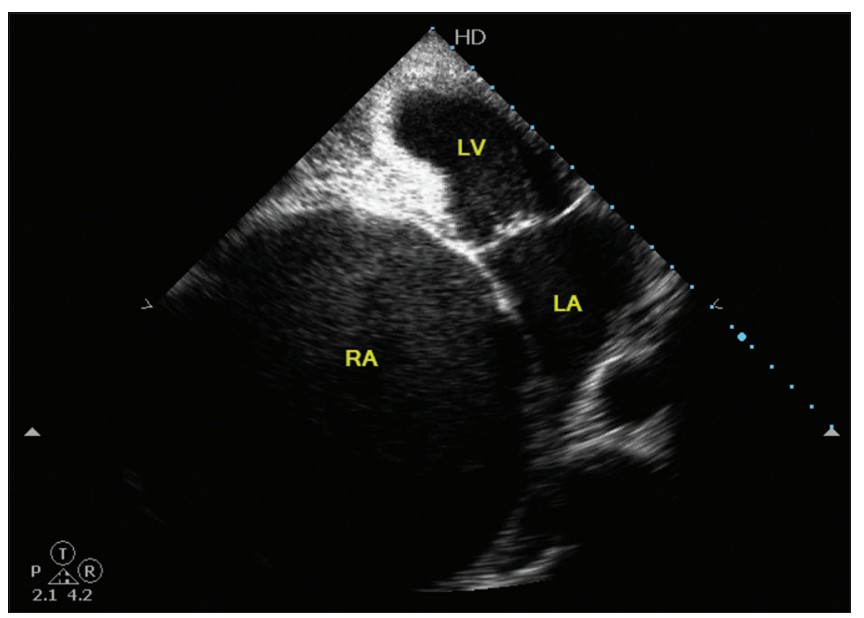

Figure 6: Transthoracic echocardiography apical four-chamber view showing a huge right atrial aneurysm

dilatation of the right atrium, while others label it as congenital enlargement of the right atrium or right atrial diverticulum. Some explanations include an intrinsic structural protein defect, abnormal collagen, or dysplastic pectinate muscles that 


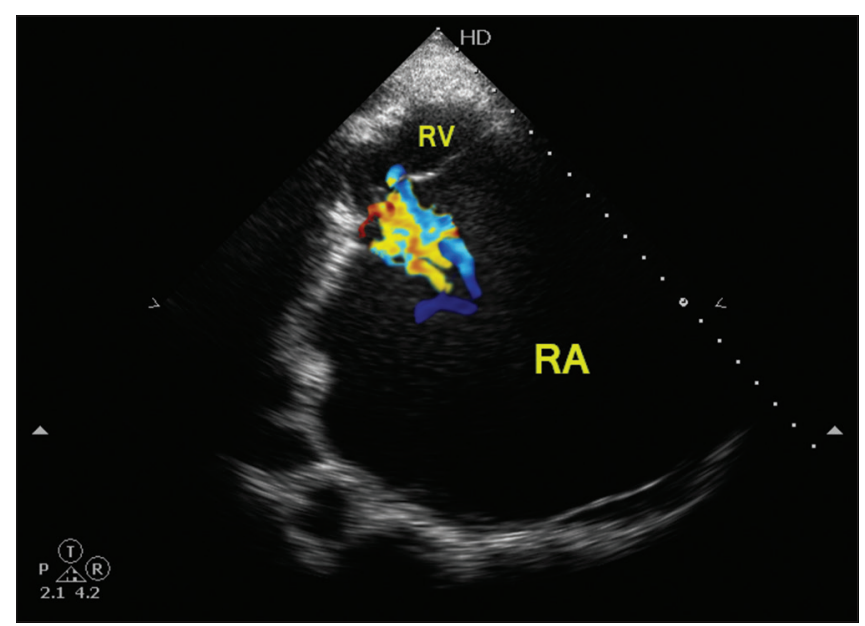

Figure 7: Transthoracic echocardiography right atrial inflow showing mild tricuspid regurgitation

make the right atrium prone to dilatation even under low right atrial pressure. ${ }^{[3]}$ So far, there are only a few case reports in the literature since Bailey first reported this condition in 1955. Age of presentation widely varies from fetal life to adulthood and elderly ${ }^{[4]}$ The majority of the patients are asymptomatic at presentation; some present with arrhythmias, palpitations, chest pain, shortness of breath, or fatigue.$^{[5]}$ Many cases are accidentally discovered by the presence of cardiomegaly on a chest X-ray during a routine checkup. Exclusion of other differential diagnoses for this condition such as Ebstein anomaly, cardiac tumors, and pericardial cysts is curtailed. The diagnosis of idiopathic giant right atrium is confirmed by TTE and/or CMR if needed. ${ }^{[6]}$ Echocardiographic evaluation of the right side with throughfall examination of the TV for any displacement, stenosis, or tricuspid annular dilation and resultant significant regurgitation of the TV modify to Echocardiographic evaluation of the right side is crucial with throughfall examination of the TV for any displacement, stenosis, or tricuspid annular dilation and resultant significant regurgitation of the $\mathrm{TV}^{\left[{ }^{[6]}\right.}$ Although sinus rhythm is reported in the majority of the cases, atrial arrhythmias such as atrial flutter and AF can also occur. Atrial arrhythmias and sluggish flow within the giant right atrium are associated with an increased risk of intra-atrial thrombus formation which predisposes to thromboembolic events such as pulmonary embolism..$^{[2]}$ Treatment options remain controversial; some reports indicate that right atrial reduction surgery should be suggested for asymptomatic patients, given the high incidence of complications such as arrhythmias and thromboembolism whereas others proceed with nonsurgical conservative treatment with continuous anticoagulation in asymptomatic patients ${ }^{[7]}$ such as our patient who refused to proceed for any further workup due to age and lack of symptoms.

\section{Conclusions}

Giant right atrial aneurysms are very rarely diagnosed, and they may be asymptomatic or may present by arrhythmias. TTE is the main tool for the diagnosis and detection of the etiology of this condition. Management usually depends on the patients' symptoms as well as their clinical condition, and it varies from conservative management with anticoagulation to surgical resection.

\section{Declaration of patient consent}

The authors certify that they have obtained all appropriate patient consent forms. In the form the patient(s) has/have given his/her/their consent for his/her/their images and other clinical information to be reported in the journal. The patients understand that their names and initials will not be published and due efforts will be made to conceal their identity, but anonymity cannot be guaranteed.

\section{Financial support and sponsorship \\ Nil.}

\section{Conflicts of interest}

There are no conflicts of interest.

\section{References}

1. Uppu SC, Sachdeva R, Imamura M. Idiopathic giant right atrial aneurysm. Ann Pediatr Cardiol 2013;6:68-70.

2. Chatrath R, Turek O, Quivers ES, Driscoll DJ, Edwards WD, Danielson GK. Asymptomatic giant right atrial aneurysm. Tex Heart Inst J 2001;28:301-3.

3. Lee Y, Cho J, Kim G, Lee S, Hyun M, Kim Y. Surgical repair of giant right atrial aneurysm in a neonate. Korean Circ J 2011;41:331-3.

4. Papagiannis J, Chatzis A, Sarris G. Giant right atrial aneurysm: A case report. Int J Cardiol 2008;129:e5-6.

5. da Silva AM, Witsemburg M, Elzenza N, Stewart P. Idiopathic dilatation of the right atrium diagnosed in utero. Rev Port Cardiol 1992;11:161-3.

6. Binder TM, Rosenhek R, Frank H, Gwechenberger M, Maurer G, Baumgartner H. Congenital malformations of the right atrium and the coronary sinus: An analysis based on 103 cases reported in the literature and two additional cases. Chest 2000;117:1740-8.

7. Yoon JW, Kim HJ, Lee SH, Kim KY, Choi SU, Bae SK, et al. A case of right atrial aneurysm incidentally found in old age. J Cardiovasc Ultrasound 2009;17:96-8. 